\title{
Theory without practice: a reply to the note from Heijungs on the average versus marginal debate in Life Cycle Impact Assessment
}

\author{
Mark A. J. Huijbregts ${ }^{1}$ (D) Stefanie Hellweg ${ }^{2} \cdot$ Edgar G. Hertwich $^{3}$
}

Received: 23 August 2021 / Accepted: 24 August 2021 / Published online: 18 October 2021

(c) The Author(s) 2021

Keywords Multistressor · Effect factor · Life cycle assessment

\section{Introduction}

Heijungs (2021) recently discussed in his note "The average versus marginal debate in Life Cycle Impact Assessment: paradigm regained" how marginal and average effect factors may be derived in a multistressor context. He derived the average multistressor effect factor as follows:

$\operatorname{msPDF}=g\left(C_{\mathrm{N}}, C_{\mathrm{P}}\right)=f 1\left(C_{\mathrm{N}}\right)+f 2\left(C_{\mathrm{P}}\right)$

$\mathrm{EF}_{\text {average, } \mathrm{N}}=\frac{f 1\left(\tilde{C}_{\mathrm{N}}\right)}{\tilde{C}_{\mathrm{N}}}$

and

$\mathrm{EF}_{\text {average }, p}=\frac{f 1\left(\tilde{C}_{\mathrm{P}}\right)}{\tilde{C}_{\mathrm{P}}}$

where msPDF is the multistressor potentially disappeared fraction due to exposure to concentration of pollutants $\mathrm{N}$ and $\mathrm{P}, g\left(C_{\mathrm{N}}, C_{\mathrm{P}}\right)$ is the mathematical expression of the combined

Communicated by Matthias Finkbeiner.

Mark A. J. Huijbregts

m.huijbregts@science.ru.nl

1 Environmental Science, Radboud Institute for Biological and Environmental Sciences (RIBES), Radboud University Nijmegen, Nijmegen, The Netherlands

2 Ecological Systems Design, Institute of Environmental Engineering, ETH Zurich, Zurich, Switzerland

3 Industrial Ecology, Department of Energy and Process Engineering, Faculty of Engineering, Norwegian University of Science and Technology (NTNU), Trondheim, Norway effect of pollutant $\mathrm{N}$ and $\mathrm{P}$, and $f 1\left(\tilde{C}_{\mathrm{N}}\right)$ and $f 2\left(\tilde{C}_{\mathrm{P}}\right)$ are the mathematical expressions of the effect caused by the background concentration of pollutant $\mathrm{N}$ and $\mathrm{P}$, respectively.

It is, however, easy to see that this way of calculating the average effect factor is not going to work which Heijungs also admits by stating that "Only by making ad hoc allocations (...) would we be able to separate the contributions, as a first step in an averaging procedure." A second argument of Heijungs against the average effect factor approach is the presumed requirement that "an average, per-item value, multiplied by the number of items, should give the total value." In more practical terms, this means that, according to Heijungs:

$\mathrm{msPDF} \approx \mathrm{EF}_{\text {average, } \mathrm{N}} \times C_{\mathrm{N}}+\mathrm{EF}_{\text {average, } \mathrm{P}} \times C_{\mathrm{P}}$

Heijungs showed with a theoretical example that Eq. 4 does not hold. Based on these two arguments - "ad hoc allocation" and "violation of the impact balance"-Heijungs concluded that "The average approach, as propagated by Huijbregts et al. (2011) ... runs into unsurmountable problems in the case of non-additive combination rules...”.

Here, we will proof that, in contrast to these statements from Heijungs, (i) ad hoc allocations are not required in the calculation of average effect factors and that (ii) the approximation of Eq. 4 is likely to hold in practice. Regardless the conceptual opportunities for both the marginal and average approaches, we conclude our reply by shortly discussing the practical obstacles to tackle before the marginal or average effect factor approaches may replace the more common linear approach.

\section{Multistressor average effect factor derivation: solution I}

It is straightforward to calculate multistressor average effect factors without ad hoc allocation upfront by changing the equations of the multistressor-based average effect factors into: 
$\mathrm{EF}_{\text {average, } \mathrm{N}}=\frac{g\left(\tilde{C}_{\mathrm{N}}, \tilde{C}_{\mathrm{P}}\right)-\lim _{C_{N} \rightarrow 0} g\left(C_{\mathrm{N}}, \tilde{C}_{\mathrm{P}}\right)}{\tilde{C}_{\mathrm{N}}-0}$

and

$\mathrm{EF}_{\text {average, } \mathrm{P}}=\frac{g\left(\tilde{C}_{\mathrm{N}}, \tilde{C}_{\mathrm{P}}\right)-\lim _{C_{\mathrm{P}} \rightarrow 0} g\left(\tilde{C}_{\mathrm{N}}, C_{\mathrm{P}}\right)}{\tilde{C}_{\mathrm{P}}-0}$

There is no need to subdivide the impact between the pollutants upfront, as suggested in Eqs. 2 and 3 by Heijungs, one just need to know the change in the multistressor impact if the stressor of interest is excluded. In full equation mode, this means that the multistressor-based average effect factor can be calculated as:

$\mathrm{EF}_{\text {average }, \mathrm{N}}=\frac{\mathrm{msPDF}_{n-\mathrm{N}}}{\tilde{C}_{\mathrm{N}}-0}=\frac{1-\left(1-\mathrm{PDF}_{\mathrm{N}}\right)\left(1-\mathrm{PDF}_{\mathrm{P}}\right)-\mathrm{PDF}_{\mathrm{N}}}{\tilde{C}_{\mathrm{N}}}$

Fig. 1 Average effect factor (option 1) vs average effect factor (option 2) in a multistressor context for $\mathrm{NO}_{3}{ }^{-}$and TP (in $\mathrm{l} /$ $\mathrm{mg}$ ), based on average monitoring concentrations in year 2011 for lakes in 35 river basins (A) and for streams in 57 river basins $(\mathbf{B})$. Data comes from Azevedo et al. (2015) and

$\mathrm{EF}_{\text {average } \mathrm{P}}=\frac{\mathrm{msPDF}_{n-\mathrm{P}}}{\tilde{C}_{\mathrm{P}}-0}=\frac{1-\left(1-\mathrm{PDF}_{\mathrm{N}}\right)\left(1-\mathrm{PDF}_{\mathrm{P}}\right)-\mathrm{PDF}_{\mathrm{P}}}{\tilde{C}_{\mathrm{P}}}$

where $\mathrm{msPF}_{n-\mathrm{N}}$ and $\mathrm{PDF}_{n-\mathrm{P}}$ are the multistressor potentially disappeared fractions caused by the total set of pressures $n$ without the contribution of the stressor under consideration $(\mathrm{N}$ or $\mathrm{P})$, and $\mathrm{PDF}_{\mathrm{N}}$ and $\mathrm{PDF}_{\mathrm{P}}$ are the potentially disappeared fractions caused by respectively pollutant $\mathrm{N}$ and P.

In words, it means that one can calculate the average effect factor as the change in the multistressor Potentially Diseappeared Fraction (msPDF) of species by putting the stress of the pollutant of interest to zero. This version of the effect factor represents the average change in the $m s P D F$ over the concentration range from ambient to zero concentration of the pollutant of interest. Note that solution I is an average approach with the underlying assumption that the pollution level of all other

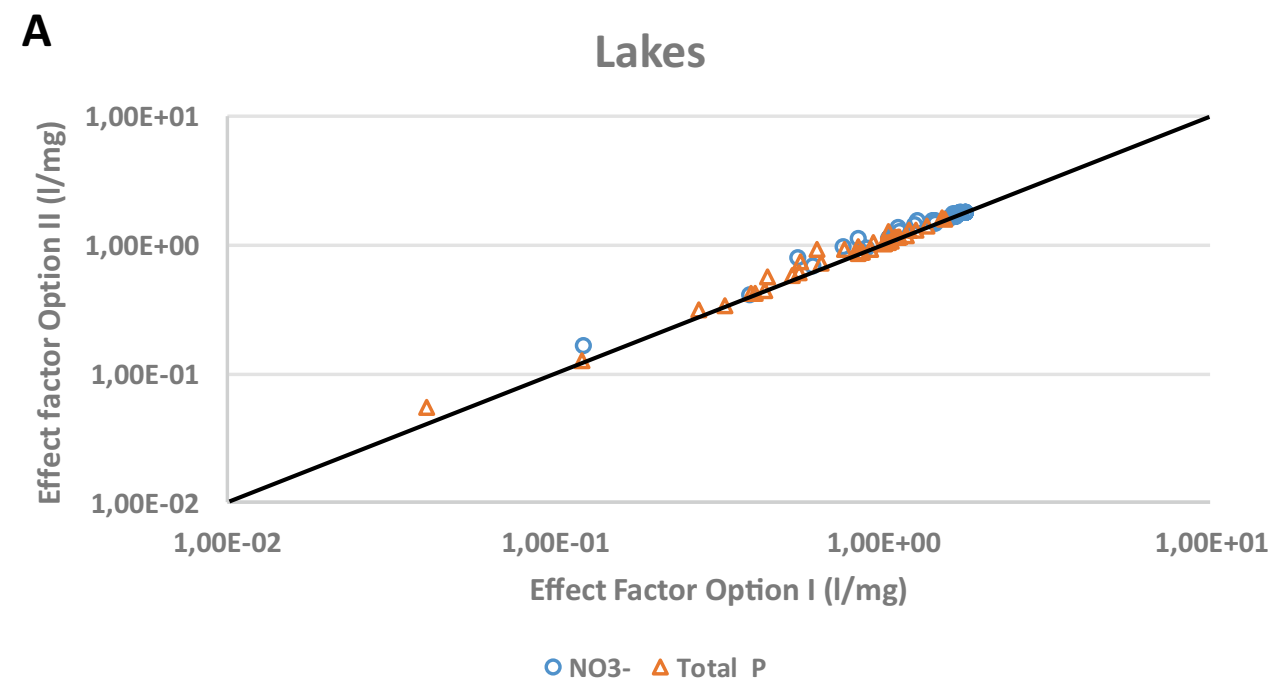

B

Streams

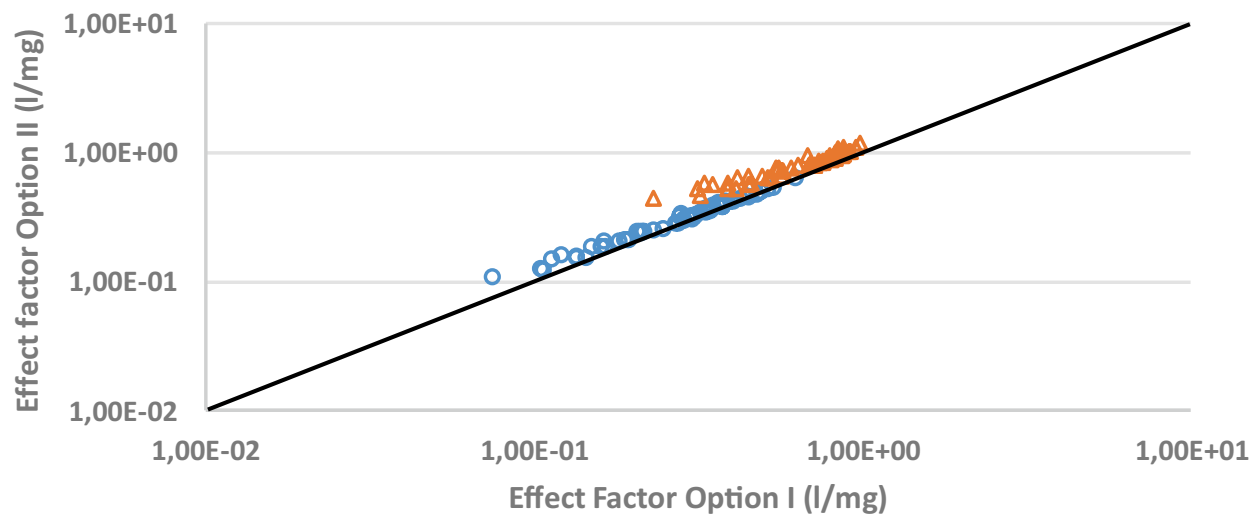

O NO3- $\Delta$ Total $P$ 
substances than the one assessed remain constant. This may be questionable, as also for those substances, we then assume a target when they are assessed, so indeed this is not a perfect approach. This means that average effect factors according to this solution cannot always be used to approximate the msPDF in a location or region. This is, however, also not the intention of Life Cycle Assessment studies where emissions related to a functional unit are evaluated.

\section{Multistressor average effect factor derivation: solution II}

As an alternative solution, the multistressor average effect factor can be calculated in a way it obeys the rule that "an average, per-item value, multiplied by the number of items, should give the total value":

$\mathrm{EF}_{\text {average }, \mathrm{N}}=\frac{\mathrm{msPDF}_{n-\mathrm{N}} / \sum_{i} \mathrm{msPDF}_{1-i}}{\tilde{C}_{\mathrm{N}}-0} \cdot \mathrm{msPDF}$

and

$\mathrm{EF}_{\text {average } \mathrm{P}}=\frac{\mathrm{msPDF}_{n-P} / \sum_{i} \mathrm{msPDF}_{1-i}}{\tilde{C}_{\mathrm{P}}-0} \cdot \mathrm{msPDF}$

where msPDF is the multistressor potentially disappeared fraction of species, $\sum_{i} \mathrm{msPDF}_{n-i}$ equals in this example $\operatorname{msPDF}_{n-\mathrm{N}}+\operatorname{msPDF}_{n-\mathrm{P}}$. This way of allocating impacts to individual stressors is conceptually equal to the way average characterisation factors are derived for different types of land occupation with non-linear species area relationships (see Chaudhary et al. 2015). It is also consistent with the way the relative importance of individual stressors to the overall impact on species abundance is derived in biodiversity modeling (Schipper et al., 2020).

\section{Practical example: eutrophication in European lakes and rivers}

To show how the two solutions work in practice, we derived average effect factors for nitrate (NO3-) and total phoshorous (TP) for lakes and streams in Europe. We used response relationships for invertebrates, determined for the two stressors (i.e., NO3- and TP) in two freshwater types (i.e., lake and stream) combined with average monitoring concentrations in European river basins for year 2011, as reported in Azevedo et al. (2015). We found that the differences between the two average effect factor solutions are always smaller than a factor of 1.5 (Fig. 1). Given the many sources of uncertainty and variability in the derivation of characterisation factors for eutrophication (see e.g.
Azevedo et al. 2013), we do not consider this factor of 1.5 relevant from a practical point of view.

\section{Conclusion}

In summary, there is no mathematical proof that a multistressor-based average effect factor is ill-defined as we have shown here. On the contrary, there are even two possible solutions for the issues identified by Heijungs. We also showed with a practical example of eutrophication impacts in European river basins that both average approaches give approximately the same results, implying that a violation of the impact balance by the approximation of solution I is not likely to occur. This means that there are, conceptually speaking, no winners or losers in the average vs marginal debate in Life Cycle Impact Assessment.

Whether average and marginal (multi-stressor) effect factors can be calculated in practice with the data available, is, however, another question that remains to be answered. Although we were able to derive average effect factors of invertebrate species for the nitrogen and phoshorus pollution in European lakes and rivers, the situation is different for the vast majority of other stressors. In practice, most effect factors, particularly for chemicals, are derived by linear extrapolation without marginal nor average considerations (see e.g. Huijbregts et al. 2017). The linear assumption is simply an admission of our own ignorance on the functional form and shape of the response relations and the environmental background situation for the vast majority of pressures. The priority of future efforts should thus lie in obtaining reliable fate, exposure, and effects information.

Acknowledgements We thank Reinout Heijungs for his comments on earlier drafts of our reply.

Open Access This article is licensed under a Creative Commons Attribution 4.0 International License, which permits use, sharing, adaptation, distribution and reproduction in any medium or format, as long as you give appropriate credit to the original author(s) and the source, provide a link to the Creative Commons licence, and indicate if changes were made. The images or other third party material in this article are included in the article's Creative Commons licence, unless indicated otherwise in a credit line to the material. If material is not included in the article's Creative Commons licence and your intended use is not permitted by statutory regulation or exceeds the permitted use, you will need to obtain permission directly from the copyright holder. To view a copy of this licence, visit http://creativecommons.org/licenses/by/4.0/.

\section{References}

Azevedo LB, Henderson AD, Van Zelm R, Jolliet O, Huijbregts MAJ (2013) Assessing the importance of spatial variability versus model choices in life cycle impact assessment: the case 
of freshwater eutrophication in Europe. Environ Sci Technol 47:13565-13570. https://doi.org/10.1021/es403422a

Azevedo LB, Van Zelm R, Leuven RSEW, Hendriks AJ, Huijbregts MAJ (2015) Combined ecological risks of nitrogen and phosphorus in European freshwaters. Environ Pollut 200:85-92. https:// doi.org/10.1016/j.envpol.2015.02.011

Chaudhary A, Verones F, De Baan L, Hellweg S (2015) Quantifying land use impacts on biodiversity: combining species-area models and vulnerability indicators. Environ Sci Technol 49:9987-9995. https://doi.org/10.1021/acs.est.5b02507

Heijungs R (2021) The average versus marginal debate in LCIA: paradigm regained. Int J Life Cycle Assess 26:22-25. https://doi.org/ 10.1007/s11367-020-01835-4

Huijbregts MAJ, Hellweg S, Hertwich E (2011) Do we need a paradigm shift in life cycle impact assessment? Environ Sci Technol 45:3833-3834. https://doi.org/10.1021/es200918b
Huijbregts MAJ, Steinmann ZJN, Elshout PMF et al (2017) ReCiPe2016: a harmonised life cycle impact assessment method at midpoint and endpoint level. Int J Life Cycle Assess 22:138-147. https://doi.org/10.1007/s11367-016-1246-y

Schipper AM, Hilbers JP, Meijer JR, Antão LH, Benítez-López A, De Jonge MMJ, Leemans LH, Scheper E, Alkemade R, Doelman JC, Mylius S, Stehfest E, Van Vuuren DP, Van Zeist WJ, Huijbregts MAJ (2020). Projecting terrestrial biodiversity intactness with GLOBIO 4. Global Change Biology 26:760-771. https://doi.org/ $10.1111 / \mathrm{gcb} .14848$

Publisher's Note Springer Nature remains neutral with regard to jurisdictional claims in published maps and institutional affiliations. 